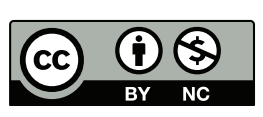

Revista Galega de Administración Pública, EGAP Núm. 61_xaneiro-xuño 2021 | pp. 195-204 Santiago de Compostela, 2021 https://doi.org/10.36402/regap.v0i61.4785

(c) Daniel Neira Barral

ISSN-e: 1132-8371 | ISSN: 1132-8371

Recibido: 02/06/2021 | Aceptado: 16/06/2021

Editado baixo licenza Creative Commons Atribution 4.0 International License

\title{
Os efectos da Directiva ECN+ no sistema de competencia español Los efectos de la Directiva ECN+ en el sistema de competencia español
} in the Spanish legal system

DANIEL NEIRA BARRAL

Vogal da Comisión Galega da Competencia

Profesor asociado de Dereito Internacional Público

Universidade de Santiago de Compostela

https://orcid.org/0000-0003-1609-9714

daniel.neira@usc.es

Resumo: Tanto a propia Directiva ECN+ (arts. 2.1.1 e 2.1.2) obxecto de transposición como o Regulamento $1 / 2002$ (arts. 35.1 e 35.2) prevén, de xeito claro, a posibilidade de que un Estado membro conte con máis dunha autoridade administrativa nacional de competencia. Esta é precisamente a situación de España, que conta constitucionalmente cun sistema administrativo descentralizado en materia de defensa e promoción da competencia.

Palabras clave: Directiva, ECN+, autoridade nacional de competencia (ANC), autoridade administrativa nacional de competencia (AAC), real decreto lei.

Resumen: Tanto la propia Directiva ECN + (arts. 2.1.1 y 2.1.2) objeto de transposición como el Reglamento 1/2002 (arts. 35.1 y 35.2) contemplan, de manera clara, la posibilidad de que un Estado miembro cuente con más de una autoridad administrativa nacional de competencia. Esta es precisamente la situación de España, que cuenta constitucionalmente con un sistema administrativo descentralizado en materia de defensa y promoción de la competencia. 
Palabras clave: Directiva, ECN+, autoridad nacional de competencia (ANC), autoridad administrativa nacional de competencia (AAC), real decreto ley.

Abstract: ENC+ Directive (arts. 2.1.1 and 2.1.2) and Regulation 1/2002 (arts. 35.1 and 35.2) clearly contemplate the possibility of a Member State having more than one authority administrative jurisdiction. This is precisely the situation in Spain, which constitutionally has a decentralized administrative system for the defense and promotion of competition.

Key words: Directive, ECN+, national competition authority (NCA), national administrative competition authority (NCAA), royal decree-law.

SUMARIO: 1 Introdución. 2 A directiva ECN+. 3 A transposición da ECN+. 4 A reforma da LDC. 5 Conclusións.

\section{Introdución}

A Directiva (UE) 2019/1 do Parlamento Europeo e do Consello, do 11 de decembro de 2018 (Directiva ECN+), dítase encamiñada a dotar as autoridades de competencia dos Estados membros de medios para aplicar máis eficazmente as normas sobre competencia e garantir o correcto funcionamento do mercado interior ${ }^{1}$, destacando que un dos principais obxectivos que se deben harmonizar é a asistencia mutua para garantir o bo funcionamento do mercado interior e o bo funcionamento do sistema de cooperación estreita dentro da rede europea de competencia, argumento que se tratará neste artigo de facer extensivo aos vínculos, desenvolvemento e recoñecemento dos distintos organismos autonómicos de defensa da competencia.

Resulta indiscutible, tal como reza o artigo $2^{2}$ da Directiva $\mathrm{ECN}+$, que por «autoridade nacional de competencia» (ANC) identificaremos aquela autoridade designada por un Estado membro de conformidade co artigo 35 do Regulamento (CE) n. 1/2003, como responsable da aplicación dos artigos 101 e 102 do TFUE, sendo no modelo español a Comisión Nacional de Mercados e da Competencia (CNMC), pero non obviando que o texto continúa habilitando os Estados membros a designar unha ou máis autoridades administrativas de competencia (autoridades administrativas nacionais de competencia -AAC-) para desempeñar todas ou algunhas das funcións da autoridade nacional de competencia.

Así, tanto a propia Directiva ECN+ (arts. 2.1.1 e 2.1.2) como o Regulamento 1/20033 (arts. 35.1 e 35.2) contemplan, de xeito claro, a posibilidade de que un Estado membro

\footnotetext{
Directiva (UE) 2019/1 do Parlamento Europeo e do Consello, do 11 de decembro de 2018, artigo 1.2. Esta directiva abrangue a aplicación dos artigos 101 e 102 do TFUE e a aplicación en paralelo do dereito nacional de competencia ao mesmo asunto. Na materia regulada polo artigo 31, apartados 3 e 4 desta directiva, abrangue tamén o dereito nacional de competencia aplicado de xeito independente. Acceso web: https://eur-lex.europa.eu/legal-content/ES/TXT/PDF/?uri=CELEX:32019L000 $1 \&$ from $=$ es.

2 Artigo 2.1. «autoridade nacional de competencia»: a autoridade designada por un Estado membro de conformidade co artigo 35 do Regulamento (CE) n. 1/2003 como responsable da aplicación dos artigos 101 e 102 do TFUE. Os Estados membros poderán designar unha ou máis autoridades administrativas de competencia (autoridades administrativas nacionais de competencia), así como autoridades xudiciais de competencia (autoridades xudiciais nacionais de competencia.

3 Regulamento (CE) 1/2003 do Consello do 16 de decembro de 2002, relativo á aplicación das normas sobre competencia previstas nos artigos 81 e 82 do tratado.
} 
conte con máis dunha autoridade administrativa nacional de competencia e esta é, precisamente, a situación de España, que conta constitucionalmente cun sistema administrativo descentralizado en materia de defensa e promoción da competencia.

Debemos precisar xa que non nos atopamos ante a análise dun novo modelo, posto que, máis alá da política de competencia, esta mesma situación -isto é, contar con máis dunha autoridade administrativa para os efectos de aplicación da lexislación comunitaria- prodúcese noutros ámbitos do ordenamento xurídico, como poden ser, sen ánimo ningún de exhaustividade, en materia de consumo ou de protección de datos ${ }^{4}$. Por iso, a reforma da $\mathrm{LDC}^{5}$ debería mencionar e recoñecer as autoridades autonómicas de competencia (AAC) como "autoridades administrativas designadas para desempeñar todas ou algunhas das funcións da autoridade nacional de competencia" segundo o previsto no artigo 2.1.2 da Directiva ECN+, co obxecto de garantir un verdadeiro espazo común de aplicación da normativa de competencia na Unión que ofreza unhas condicións de competencia máis equitativas ás empresas que operan no mercado interior e reduza a desigualdade de condicións dos consumidores, sendo necesario establecer, á vez, unhas garantías de independencia, uns recursos financeiros, humanos, técnicos e tecnolóxicos axeitados, así como unhas competencias mínimas de aplicación e imposición de multas ao aplicar os artigos 101 e 102 do TFUE, de modo que as autoridades administrativas nacionais de competencia poidan ser plenamente eficaces ${ }^{6}$.

\section{A directiva ECN+}

O principal obxecto e finalidade da Directiva ECN+ é garantir o bo funcionamento do mercado interior, obxectivo que se entenderá satisfeito coa implantación de normas relativas á asistencia mutua e bo funcionamento do sistema de cooperación por parte dos órganos de control, que debera ser estreita dentro da rede europea de competencia e que, por extensión, interpretamos que debera reproducirse a nivel interno naqueles Estados membros que dispoñan dunha ordenación institucional e orgánica descentralizada. Por iso e para iso, xa no seu artigo 2 se identifican, definen e habilitan dous instrumentos, a «autoridade nacional de competencia» á cal nos referiremos como ANC e a «autoridade administrativa nacional de competencia», referida como $\mathrm{AAC}^{7}$.

\footnotetext{
Neste sentido, a Lei orgánica 3/2018, do 5 de decembro, de protección de datos persoais e garantía dos dereitos dixitais, é clara no seu artigo 61 ao establecer:

«1. As autoridades autonómicas de protección de datos terán a condición de autoridade de control principal ou interesada no procedemento establecido polo artigo 60 do Regulamento (UE) 2016/679 cando se refira a un tratamento previsto no artigo 57 desta lei orgánica que levase a cabo un responsable ou encargado do tratamento dos previstos no artigo 56 do Regulamento (UE) 2016/679, salvo que desenvolvese significativamente tratamentos da mesma natureza no resto do territorio español.

2. Corresponderalles nestes casos ás autoridades autonómicas intervir nos procedementos establecidos no artigo 60 do Regulamento (UE) 2016/679, informando a Axencia Española de Protección de Datos sobre o seu desenvolvemento nos supostos en que deba aplicarse o mecanismo de coherencia». (Acceso web: https://www.boe.es/buscar/doc.php?id=BOE-A-2018-16673).

5 Lei 15/2007, do 3 de xullo, de defensa da competencia.

6 Conforme reza parte do Considerando 8 da Directiva ECN+.

Artigo 2. Definicións,

1. Para os efectos desta directiva, enténdese por:
} 
O lexislador comunitario incide na necesidade de lograr unha independencia operativa das autoridades administrativas nacionais de competencia (AAC) reforzándose co fin de garantir a aplicación eficaz e uniforme dos artigos 101 e 102 do TFUE. Para iso, expón, debe disporse expresamente no dereito nacional que, ao aplicar os artigos 101 e 102 do TFUE, as autoridades administrativas nacionais de competencia estean protexidas de intervencións externas ou presións políticas que poidan comprometer a súa avaliación independente dos asuntos que lles fosen sometidos.

Para tal efecto, deben establecerse por exemplo, de antemán, no dereito nacional os motivos para a revogación por parte das autoridades administrativas nacionais de competencia daquelas persoas que toman decisións no exercicio das competencias definidas nos artigos 10,11, 12, 13 e 16 da directiva, co fin de disipar calquera dúbida razoable respecto á súa imparcialidade e a súa impermeabilidade a factores externos. Do mesmo xeito, deben establecerse previamente no dereito nacional normas e procedementos claros e transparentes para a selección, a contratación ou o nomeamento desas persoas.

Así mesmo, co fin de asegurar a imparcialidade das autoridades administrativas nacionais de competencia, estas autoridades non deben utilizar as multas que impoñan por infraccións dos artigos 101 e 102 do TFUE para financiarse directamente, aínda que si se poderán prever distintas formas de financiamento, tales como fontes alternativas distintas do orzamento do Estado, para garantir que as autoridades administrativas nacionais de competencia conten cos recursos necesarios para o desempeño das súas funcións ${ }^{8}$.

Na comparecencia da presidenta da Comisión Nacional dos Mercados e a Competencia en relación coa análise das medidas necesarias para reforzar a imparcialidade e independencia de autoridades independentes e organismos de regulación ante a Comisión para a auditoría da calidade democrática, a loita contra a corrupción e as reformas institucionais e legais do Congreso dos Deputados do 3 de febreiro de $2021^{9}$, conclúese que "a Lei de creación da CNMC estableceu un réxime rigoroso en relación coa independencia da CNMC, excepto no que se refire á autonomía de xestión dos seus recursos humanos, estrutura organizativa e orzamento". Con todo, "as previsións da LCNMC relativas á independencia institucional, legal e financeira alcanzan os niveis axeitados e cumpren coas exixencias das directivas comunitarias"; aínda así, "a CNMC necesita autonomía para organizar de forma coherente e efectiva o seu equipo humano, a súa estrutura e o seu orzamento (...) a CNMC funciona como unha unidade adscrita a calquera Ministerio (...) en definitiva, a plena autonomía dos organismos reguladores debe ser interna e externa, na forma e no fondo, tal como exixen as directivas comunitarias".

\footnotetext{
1) «autoridade nacional de competencia»: a autoridade designada por un Estado membro de conformidade co artigo 35 do Regulamento (CE) 1/2003 como responsable da aplicación dos artigos 101 e 102 do TFUE. Os Estados membros poderán designar unha ou máis autoridades administrativas de competencia (autoridades administrativas nacionais de competencia), 2) «autoridade administrativa nacional de competencia»: a autoridade administrativa designada por un Estado membro para desempeñar todas ou algunhas das funcións da autoridade nacional de competencia.

8 Considerando 17 e 26 da Directiva ECN+. p\%C3\%BAblicas/20210302_Comparacencia_Congreso_Comisi\%C3\%B3n_Calidad\%20Democr\%C3\%A1tica_web.pdf.
} 
Así, falando de ECN+, no procedemento de transposición, os órganos estatais deben formularse de forma explícita e reflexiva a cuestión da distribución competencial entre o Estado e as comunidades autónomas (CC.AA.), de forma que ponderen o alcance das competencias estatais na materia sobre a que versa a directiva e a finalidade e obxecto desta.

España conta constitucionalmente cun sistema administrativo descentralizado en materia de defensa e promoción da competencia; por iso, a LDC debera recoñecer as autoridades autonómicas de competencia como "autoridades administrativas designadas por un Estado membro para desempeñar todas ou algunhas das funcións da autoridade nacional de competencia", segundo o previsto no artigo 2.1.2 da Directiva ECN+. Esta consideración de autoridade administrativa nacional de competencia, pola cal se desempeñan todas ou algunhas das funcións da Autoridade Nacional da Competencia, implica o necesario recoñecemento ás autoridades autonómicas da consecuente facultade de aplicación dos artigos 101 e 102 do TFUE.

En conexión co descrito, é de interese sinalar que as autoridades autonómicas gozan da inherente, que non recoñecida, facultade de aplicación dos artigos 101 e 102 do TFUE, como sucede, por exemplo, coas autoridades de competencia dos länder en Alemaña, onde teñen competencia para aplicar a normativa da Unión Europea cando a conduta limite os seus efectos á rexión, pero teña incidencia no mercado interior ${ }^{10}$.

A Lei $1 / 2002^{11}$ supuxo a materialización da descentralización da política de competencia recoñecida polo Tribunal Constitucional e, posteriormente, recollida en moitas das reformas dos estatutos de autonomía12. Así, á vista da doutrina xurisprudencial ${ }^{13}$, cabe afirmar que o desenvolvemento normativo do dereito europeo no Estado autonómico lle corresponde ao poder público materialmente competente para regular esa materia de acordo coas regras internas de repartición competencial.

Non se trata dunha facultade competencial (nin o Estado nin as CC. AA. posúen un título competencial específico para a aplicación interna do dereito europeo), senón que se trata dunha función derivada de e vinculada a un título competencial material. Polo tanto, a xeito de resumo, debe significarse que no desenvolvemento normativo do dereito europeo rexe o principio de non alteración da repartición competencial.

${ }^{10}$ CANEDO ARRILLAGA, M.P., "Una visión comparada de la descentralización en la aplicación de la normativa de competencia en Europa", Revista de Derecho de la Unión Europea, n. 30 (xaneiro-xuño), n. 31 (xullo-decembro), 2016, pp. 107-142.

11 Lei 1/2002, do 21 de febreiro, de coordinación das competencias do Estado e as comunidades autónomas en materia de defensa da competencia.

12 As competencias das CC. AA. para aplicar a normativa de competencia son recoñecidas polas STC 208/1999, STC 31/2010 e STC 71/2012, así como polos propios estatutos de autonomía. Art. 58.1.5, art. 58.4.5 e art. 164 do EA para Andalucía; art. 71.24 e art. 77.17 do EA de Aragón; art. 154 do EA de Cataluña; art. 10.27 do EA do País Vasco, art. 30.4 EA de Galicia.

13 STC 79/1992, cuxo fundamento xurídico primeiro dispón que a translación da normativa comunitaria derivada ao dereito interno debe seguir necesariamente os criterios constitucionais e estatutarios de repartición de competencias entre o Estado e as comunidades autónomas.

A STC 236/1991 ditada en relación coa competencia en materia de pesos e medidas engadiu que: «as canles correspondentes (art. 95.1 CE) non resultan alteradas nin polo ingreso de España na Comunidade Europea nin pola promulgación de normas comunitarias», polo que «a execución do Dereito comunitario corresponde a quen materialmente teña a competencia, segundo as regras de dereito interno».

SSTC 76/1991, 236/1991, 79/1992, 146/1996, 33/2005 e 134/2011, "principio xeral da non alteración da orde interna de distribución de competencias".

A STC 76/1991 estableceu que a aplicación do Dereito da Unión en materia de agricultura corresponde ao Estado ou ás CC. AA. segundo quen fose o titular da competencia afectada pola norma europea. 
En consecuencia, a aplicación interna do dereito europeo corresponde a quen «materialmente», ou «naturalmente», teña a competencia segundo as regras de dereito interno; por iso, ás CC.AA. corresponderalles a aplicación de normas europeas, en canto titulares de competencias, en atención ao grao de intervención que resulte dos respectivos estatutos para esas materias competenciais ${ }^{14}$, levándonos á conclusión de que, se isto é así, as autoridades autonómicas de competencia non só teñen independencia na súa actuación, senón que deberían ser consideradas na axeitada dotación de recursos para a transposición material, por exemplo, do capítulo III de Directiva ECN+.

\section{A transposición da ECN+}

Mediante o Real Decreto-lei $7 / 2021^{15}$, concretamente no seu título I, que comprende os artigos primeiro e segundo, contéñense as modificacións derivadas da transposición da Directiva (UE) 2019/1 do Parlamento Europeo e do Consello, do 11 de decembro de 2018, encamiñada a dotar as autoridades de competencia dos Estados membros de medios para aplicar máis eficazmente as normas sobre competencia e garantir o correcto funcionamento do mercado interior (Directiva ECN+).

Desde un prisma meramente formal e de técnica xurídica, destaca inicialmente a xustificación do instrumento xurídico utilizado, referenciando ao Tribunal Constitucional fronte á situación de extraordinaria e urxente necesidade que exixe, como presuposto habilitante, artigo 86.1 da Constitución española, que se poida deducir «dunha pluralidade de elementos», entre eles, «os que quedan reflectidos na exposición de motivos da norma» (STC 6/1983, do 4 de febreiro).

Na situación de extraordinaria e urxente necesidade, que habilita o emprego do real decreto-lei, as medidas contidas nel deben ter unha relación directa ou de congruencia co extraordinario e urxente. Así, para a concorrencia da extraordinaria e urxente necesidade, a STC 61/2018, do 7 de xuño (FX 4), exixe, por unha banda, «a presentación explícita e razoada dos motivos que foron tidos en conta polo Goberno para a súa aprobación», é dicir, o que veu denominarse a situación de urxencia; e, por outro, «a existencia dunha necesaria conexión entre a situación de urxencia definida e a medida concreta adoptada para axudar a esta».

Sendo isto así, resáltase, na mesma exposición, que "o prazo de transposición da Directiva ECN+ venceu o pasado 4 de febreiro de 2021 e que se recibiu carta de emprazamento da Comisión datada o pasado 18 de marzo para a súa contestación no prazo de dous meses, existindo un procedemento de infracción aberto", o que invita a pensar e deducir que a posibilidade de que a concorrencia do presuposto da extraordinaria e urxente necesidade para a aprobación do Real Decreto-lei 7/2021

\footnotetext{
14 ESPEJO CAMPOS, A., "La transposición del derecho de la Unión Europea por las comunidades autónomas", Anales de la Facultad de Derecho, n. 29, 2012, pp. 139-160.

15 Real Decreto-lei 7/2021, do 27 de abril, de transposición de directivas da Unión Europea nas materias de competencia, prevención do branqueo de capitais, entidades de crédito, telecomunicacións, medidas tributarias, prevención e reparación de danos ambientais, desprazamento de traballadores na prestación de servizos transnacionais e defensa dos consumidores. Acceso web: https://www.boe.es/buscar/act.php?id=BOE-A-2021-6872.
} 
se basea no argumentario da necesaria adecuación á Directiva ECN+ do sistema de defensa da competencia español, encabezado pola Comisión Nacional dos Mercados e a Competencia (CNMC) como ANC - sen prexuízo das facultades dos organismos de competencia autonómicos (AAC) - , facendo necesario modificar a Lei 15/2007, do 3 de xullo, de defensa da competencia, para garantir a plena adecuación ás previsións do dereito europeo e realizar algunha modificación puntual na Lei 3/2013, do 4 de xuño, de creación da Comisión Nacional dos Mercados e a Competencia. Ou se, pola contra, a extraordinaria e urxente necesidade da aprobación do Real Decretolei 7/2021 vén derivada e xustificada ante un inminente risco de multa con base no establecido no artigo 260.3 do TFUE, ao se teren recibido as correspondentes cartas de citación e existir un procedemento de infracción aberto pola Comisión, evitando así as consecuencias de seguir acumulando atraso na incorporación ao ordenamento xurídico español de tales directivas, resultando necesario acudir á aprobación dun real decreto-lei para proceder a esa transposición, o que permitirá pechar (en falso) os procedementos de infracción abertos pola Comisión Europea ${ }^{16}$ por non acometer as reformas que dimanan da Directiva 2019/1 (ECN+).

Aínda que formalmente puidesen existir certas dúbidas sobre a xustificación da extraordinaria e urxente necesidade, co evidente risco de que a xustificación que o real decreto-lei analizado ofrece sobre a urxencia que o promoveu sexa admisible ${ }^{17}$, en canto ao contido do citado instrumento, e despois do argumentado en apartados anteriores, a referencia á realidade autonómica soluciónase vagamente e cunha mera mención asociada á idea de que, dentro do sistema de defensa da competencia español, lle corresponde á Comisión Nacional dos Mercados e a Competencia (CNMC) como $\mathrm{ANC}^{18}$ o papel de garante da competencia nos mercados no ámbito nacional, "sen prexuízo das facultades dos organismos de competencia autonómicos".

\section{A reforma da LDC}

Con Resolución do 13 de maio de 2021, do Congreso dos Deputados, ordénase a publicación do Acordo de validación do Real Decreto-lei 7/2021, do 27 de abril, de transposición de directivas da Unión Europea nas materias de competencia, prevención do branqueo de capitais, entidades de crédito, telecomunicacións, medidas tributarias, prevención e reparación de danos ambientais, desprazamento de traballadores na prestación de servizos transnacionais e defensa dos consumidores (BOE do 19 de maio de 2021) ${ }^{19}$.

\footnotetext{
16 Asunto C-658/19 Comisión/España. Condénase a España a pagar unha suma a tanto alzado de 15.000 .000 de euros e unha multa coercitiva diaria de 89.000 euros por non traspor aínda unha directiva nin comunicar as medidas de transposición desta. Trátase da Directiva de protección de datos persoais no marco da prevención e detección de infraccións penais. Acceso web: https://curia.europa.eu/jcms/upload/docs/application/pdf/2021-02/cp210022es.pdf.

17 STC 6/1983 FX5, STC11/2002 FX4, STC137/2003 FX3 ou STC189/2005 FX3.

18 Utilízanse as siglas ANC para identificar a CNMC, obviando referenciar, por exemplo, os órganos autonómicos, como AAC, tal como define a directiva.

19 Acceso web: https://www.boe.es/boe/dias/2021/05/19/pdfs/BOE-A-2021-8265.pdf.
} 
Nela consta a mención á necesidade dunha transposición parcial da directiva coñecida como ECN+ no ámbito da defensa da competencia, (...) unha directiva cuxo obxectivo é proporcionarlles aos Estados membros os medios necesarios para reforzar a aplicación efectiva das normas sobre competencia e garantir o correcto funcionamento do mercado interior. Así, establécense novos instrumentos para impulsar a asistencia entre a Comisión Nacional dos Mercados e a Competencia e as autoridades dos Estados membros, concrétanse os deberes de información e colaboración e as facultades de inspección das autoridades de competencia, tamén se incrementan determinadas sancións, dáse a posibilidade á Comisión Nacional dos Mercados e a Competencia de rexeitar denuncias sobre a base de criterios de priorización e créanse maiores incentivos para a utilización do Programa de Clemencia (...) sen mención á posibilidade de recoñecer e fortalecer a situación dos organismos autonómicos (AAC) coas competencias descritas anteriormente, encamíñanos á espera e desexo de que na súa tramitación como proxecto de lei poidan ser emendadas certas partes deste decreto (no relativo á Directiva $\mathrm{ECN}+$ ), xa que, se se remarca a necesidade de fortalecer a relación entre ANC (CNMC) e as autoridades homólogas dos Estados membros, con máis necesidade resultaría facelo a nivel interno.

\section{Conclusións}

O Regulamento 1/2003 do Consello, do 16 de decembro de 2002, relativo á aplicación das normas sobre competencia previstas nos artigos 81 e 82 do tratado prevía expresamente no seu artigo 35 a posibilidade de designar distintas autoridades nacionais de competencia dentro dun Estado membro ${ }^{20}$.

A posibilidade de que os Estados membros designen máis dunha autoridade de competencia para a aplicación dos artigos 101 e 102 TFUE tamén foi recollida pola máis recente Directiva ECN+ (2019/1) no seu artigo 2.

A validación do Real Decreto-lei 7/2021 como proxecto de lei que guíe a modificación da actual Lei de defensa da competencia (LDC) ${ }^{21}$ debería moldear o sistema descentralizado de autoridades administrativas de competencia existente en España, de forma que ao longo dos seus preceptos se referenciase ao sistema español de defensa da competencia, no seu conxunto, salvo naqueles supostos puntuais en que a mención deba ser específica á CNMC ou ás autoridades autonómicas de competencia; para iso, resultaría útil, xa nos seus primeiros articulados, a definición e alcance subxectivo da lei tanto da ANC como a AAC conforme a directiva 2019/1, levando isto a un recoñecemento das autoridades autonómicas da facultade de aplicación dos artigos 101 e 102 do TFUE, como de facto se fai.

O recoñecemento por parte da futura LDC do ámbito e alcance nas actuacións das autoridades autonómicas de competencia condicionado á estreita colaboración coa ANC

\footnotetext{
"Designación das autoridades de competencia dos Estados membros.

1. Os Estados membros designarán a autoridade ou autoridades de competencia competentes para aplicar os artigos 81 e

82 do Tratado de tal forma que poidan velar polo cumprimento efectivo do disposto neste regulamento".

${ }^{21}$ Lei 15/2007, do 3 de xullo, de defensa da competencia.
} 
(CNMC) adecuando o órgano e os mecanismos de coordinación (como, por exemplo, incorporar a condición de interesado da AAC en expedientes levados pola CNMC que afecten de xeito significativo ao ámbito territorial desas AAC), así como os puntos de conexión e contemplar mecanismos que eviten duplicidades reduciría o uso ineficiente de recursos públicos e reforzaría non só a independencia dos instrumentos de defensa da competencia a nivel interno (ANC-AAC), senón tamén o seu argumentario en relación coa necesaria dotación dos recursos para o cumprimento dos seus fins, pois só así se podería entender axeitadamente trasposta a Directiva ECN+.

Así, a futura LDC debería recoñecer de forma expresa e clara a necesidade de garantir a independencia das autoridades autonómicas de competencia reforzando os instrumentos e medios á súa disposición, declarando na LDC que as AAC gozarán na súa actuación de "plena independencia e da axeitada dotación de recursos para cumprir as súas funcións", cumprindo dese xeito cos obxectivos que persegue a Directiva ECN+. Tamén incluír un artigo no que se indique, de xeito similar ao disposto na lexislación alemá, que "o Sistema Español de Defensa da Competencia está constituído pola CNMC e polas AAC".

Resultaría de interese integrar o contido da Lei 1/2002 de coordinación de competencias na Lei 15/2007, do 3 de xullo, de defensa da competencia, para regular nun só texto lexislativo as disposicións estatais aplicables ao Sistema Español de Defensa da Competencia.

Nas relacións entre a CNMC e as AAC deberíase aplicar o principio de "Autoridade mellor situada", que consagra o Regulamento (CE) n. 1/2003 do Consello, do 16 de decembro de 2002, relativo á aplicación das normas sobre competencia previstas nos artigos 81 e 82 do tratado (101 e 102).

De igual forma, resultaría relevante incluír a condición de interesado das AAC nos expedientes levados pola CNMC que afecten de xeito significativo ao ámbito territorial desas AAC.

En consecuencia, tal e como se recolle nos considerandos da propia Directiva $\mathrm{ECN}+$, ben se podería tomar a literalidade do texto descrito a continuación cando se reflexione sobre estas necesidades para coas institucións e organismos de control autonómicos e, así, a directiva comunitaria reza que "a aplicación desigual dos artigos 101 ou 102 do TFUE, xa sexa de xeito independente ou en paralelo co Dereito nacional da competencia, se traduce na perda de oportunidades para eliminar as barreiras á entrada ao mercado e crear mercados competitivos máis abertos e xustos en todo o territorio da Unión nos cales as empresas compitan sobre a base dos seus méritos. (...)

A aplicación ineficaz que resulta diso falsea a competencia para as empresas que respectan a lei e mina a confianza dos consumidores no mercado interior, en particular no contorno dixital". 


\section{Bibliografía}

ARZOZ SANTISTEBAN, X. (dir.), Transposición de directivas y autogobierno. El desarrollo normativo del derecho de la Unión Europea en el estado autonómico, Generalitat de Catalunya, Institut d'Estudis Autonòmics, Barcelona, 2013.

CANEDO ARRILLAGA, M.P., "Una visión comparada de la descentralización en la aplicación de la normativa de competencia en Europa", Revista de Derecho de la Unión Europea, n. 30 (xaneiro-xuño), n. 31 (xullo-decembro), 2016.

ESPEJO CAMPOS, A., "La transposición del derecho de la Unión Europea por las comunidades autónomas", Anales de la Facultad de Derecho, n. 29, 2012.

MANGAS MARTÍN, A., Derecho comunitario europeo y derecho español, Tecnos, Madrid, 1986.

MANGAS MARTÍN, A., "La aplicación del Derecho comunitario por las Comunidades Autónomas", Relaciones internacionales y Comunidades Autónomas. Seminario celebrado en Barcelona el 9 de mayo de 1990, Institut d'Estudis Autonòmics, Barcelona, 1990. 